\title{
Multimarker Reverse Transcriptase-Polymerase Chain Reaction Assay in Lymphatic Drainage and Sentinel Node Tumor Burden
}

\author{
Piotr Rutkowski, MD, PhD ${ }^{1}$, Zbigniew I. Nowecki, MD, PhD ${ }^{1}$, Alexander C. J. van Akkooi, MD, PhD ${ }^{2}$, \\ Jadwiga Kulik, BSc ${ }^{3}$, Michej Wanda, $\mathrm{MD}^{4}$, Janusz A. Siedlecki, $\mathrm{PhD}^{3}$, Alexander M. M. Eggermont, MD, $\mathrm{PhD}^{2}$, and \\ Wlodzimierz Ruka, MD, PhD ${ }^{1}$
}

\begin{abstract}
${ }^{1}$ Department of Soft Tissue/Bone Sarcoma and Melanoma, Maria Sklodowska-Curie Memorial Cancer Center and Institute of Oncology, Warsaw, Poland; ${ }^{2}$ Erasmus University Medical Center, Daniel den Hoed Cancer Center, Rotterdam, The Netherlands; ${ }^{3}$ Department of Molecular Biology, Maria Sklodowska-Curie Memorial Cancer Center and Institute of Oncology, Warsaw, Poland; ${ }^{4}$ Department of Pathology, Maria Sklodowska-Curie Memorial Cancer Center and Institute of Oncology, Warsaw, Poland
\end{abstract}

\begin{abstract}
Purpose. We assessed molecular (presence of melanoma cells markers in lymph fluid [LY]) and pathological features (sentinel lymph node [SN] tumor burden according to Rotterdam criteria, metastases microanatomic location) and correlated them with survival and melanoma prognostic factors in a group of patients with positive SN biopsy.

Methods. We analyzed 368 consecutive SN-positive patients after completion lymph node dissection (CLND). In 321 patients we obtained data on SLN microanatomic location/tumor burden (only 7 cases had metastases $<0.1 \mathrm{~mm}$ ); in 137 we additionally analyzed 24-hour collected LY after CLND (multimarker reverse transcriptasepolymerase chain reaction [MM-RT-PCR] with primers for tyrosinase, MART1 (MelanA), and uMAGE mRNA (27.7\% positive samples)]. Median follow-up time was 41 months. Results. According to univariate analysis, the following factors had a negative impact on overall survival (OS): higher Breslow thickness $(P=.0001)$, ulceration $(P<$ $.0001)$, higher Clark level $(P=.008)$, male gender $(P=.0001)$, metastatic lymph nodes $>1 \quad(P<.0001)$,
\end{abstract}

\footnotetext{
The study was presented as oral presentation during 63rd Annual Cancer Symposium of Society of Surgical Oncology; March 3-7, 2010, St. Louis, MO.
}

(C) The Author(s) 2010. This article is published with open access at Springerlink.com

First Received: 3 March 2010;

Published Online: 7 July 2010

P. Rutkowski, MD, PhD

e-mail: rutkowskip@coi.waw.pl nodal metastases extracapsular extension $(P<.0001)$, metastases to additional non-SNs $(P=.0004)$, micrometastases size $\geq 0.1 \mathrm{~mm}(P=.0006)$, and positive LY MMRT-PCR $(P=.0007)$. SN tumor burden showed linear correlation with increasing Breslow thickness $(P=.01)$. The 5-year OS rates for SLN tumor burden $<0.1 \mathrm{~mm}, 1-$ $1.0 \mathrm{~mm}$, and $>1.0 \mathrm{~mm}$ were $84 \% / 66 \% / 44 \%$, respectively, and for positive and negative LY MM-RT-PCR 47\%/0\%, respectively. The independent factors for shorter OS (multivariate analysis): male gender, primary tumor ulceration, number of involved nodes $\geq 4$, micrometastases size $>1.0 \mathrm{~mm}$, and, in additional model including molecular analysis-positive MM-RT-PCR results (hazard ratio [HR] 3.2), micrometastases size $>1.0 \mathrm{~mm}$ (HR 1.13), and primary tumor ulceration (HR 2.17). Similar results were demonstrated for disease-free survival (DFS) data.

Conclusions. SN tumor burden categories according to Rotterdam criteria and the positive result of LY MM-RTPCR assay demonstrated additional, independent prognostic value in SN-positive melanoma patients, showing significant correlation with shorter DFS and OS.

Sentinel node biopsy (SNB) is currently a valuable and reliable diagnostic procedure for precise staging of cutaneous melanoma patients with clinically noninvolved regional nodes. ${ }^{1-4}$ In case of positive sentinel node biopsy the radical removal of lymph nodes of involved basin is indicated. The new 2010 American Joint Committee on Cancer (AJCC) cutaneous melanoma staging system confirmed the value of sentinel lymph node biopsy (SNB) as minimally invasive surgical procedure for microstaging of 
the presence of metastases in regional nodal basin. ${ }^{5}$ The AJCC and our previous analysis confirmed that the features of nodal metastases (number of involved nodes) and primary tumor features (e.g., presence of ulceration, tumor Breslow thickness) have the impact on patient outcome after completion lymph node dissection (CLND) due to positive SNB. ${ }^{5,6}$ However, current prognostic factors are still inadequate for precise guide of the treatment, because of the high heterogeneity of SNB-positive patients. Recent discoveries have stressed the prognostic role of SN tumor burden and microanatomic tumor deposit location. ${ }^{7-9}$ Van Akkooi et al. showed that submicrometastases $<0.1 \mathrm{~mm}$ according to the Rotterdam criteria have extremely favorable prognosis identical to patients with negative SNs. ${ }^{7,8}$

Additional disease-specific factors can provide molecular techniques. We have demonstrated previously with using two-marker or multimarker reverse transcriptasepolymerase chain reaction (MM RT-PCR) technique in the group of cutaneous melanomas with regional node metastases (microscopic and macroscopic), that positive result of this assay correlated significantly with early melanoma recurrence and shorter survival. ${ }^{10-12}$

The aim of the present study was to assess the role of these new molecular and pathologic prognostic factors and correlate them with other clinical-pathological factors and survival data in group of cutaneous melanoma SN-positive patients after CLND, treated in 1 institution.

\section{PATIENTS AND METHODS}

\section{Patient Characteristics}

We analyzed the data of 368 consecutive patients with histologically confirmed cutaneous melanoma, who underwent radical lymph node dissection (CLND) at the Department of Soft Tissue/Bone Sarcoma and Melanoma at the Maria Sklodowska-Curie Memorial Cancer Centre and Institute of Oncology, Warsaw, Poland (CCIO) between May 1995 and February 2009 because of positive SNB. The detailed technique of SNB and the pathologic examination of SNs have been already presented in our previous publications. ${ }^{4}$ The false-negative cases (defined as nodal recurrence after initially negative SLN biopsy in the biopsied basin) were excluded from the CLND group. The margin of excision of all the primaries was $\geq 1 \mathrm{~cm}$. Each patient provided written informed consent. The study was approved by the local Bio-Ethics Committee according to Good Clinical Practice Guidelines.

All patients undergoing SNB had primary cutaneous melanoma after excisional biopsy with Breslow thickness $\geq 0.75 \mathrm{~mm}$ or ulcerated or Clark level $\geq \mathrm{IV}$ (all histological diagnoses were confirmed in the Department of Pathology
CCIO) with clinically nonpalpable regional lymph nodes and without distant metastases.

The patients had not undergone any other preliminary selection. Only patients who met with all the conditions listed previously were enrolled in the study.

The clinicopathological stage of the melanoma patients was determined by pathological evaluation of the primary lesion and of the dissected lymph nodes, as well as by physical examination and routine imaging examinations (chest X-ray, ultrasound of the abdominal cavity, and computed tomography imaging, if necessary).

Patients' characteristics are summarized in Table 1. All patients had confirmed primary cutaneous melanoma. Radical lymph node dissections were performed according to the technique described by Karakousis. ${ }^{13}$ For ilioinguinal lymphadenectomy we routinely excised the superficial and deep levels below the inguinal ligament to the level of the aortic bifurcation combined with obturatory lymph node dissection. A total of 82 patients received interferon$\alpha 2 b$ as adjuvant treatment after lymphadenectomy in accord with the EORTC 18952 trial (without significant influence on survival data). ${ }^{14}$

All patients were followed carefully with a median follow-up time of 41 months for survivors (range, 6120 months). Postoperative follow-up consisted of physical examination and routine imaging investigations (chest $\mathrm{X}$ ray, ultrasound of the abdominal cavity). Routinely, surveillance was recommended every 3 months for the first 2 years, every 4 months in year 3, every 6 months for years $4-5$, and thereafter annually.

\section{Pathological Examination}

A total of 321 cases of pathological slides of the SNs were re-evaluated for the purpose of this study [by AA, WM]. It was performed according to the EORTC pathology protocol developed by Cook et al., but only $\mathrm{H} \& \mathrm{E}$ staining was performed first. ${ }^{15}$ If this was negative, other slides were stained with S100 and HMB-45. The amount of $\mathrm{SN}$ tumor burden was measured according to the Rotterdam criteria, which consist of the following: measure the maximum diameter (in any direction) of the largest lesion on a slide. ${ }^{7}$ All positive slides are examined, and this process of measuring the largest lesion is repeated. The largest value overall (which is the largest diameter measured anywhere on 1 slide in 1 patient) has been defined as the amount of SN tumor burden (in $\mathrm{mm}$ ). If a patient had multiple positive SNs, the largest maximum diameter of any of the SNs is the largest overall and thus the amount of $\mathrm{SN}$ tumor burden for this patient. Categories were made for SN tumor burden as follows: $<0.1 \mathrm{~mm}$ (submicrometastases), $0.1-1.0 \mathrm{~mm}$, and $>1.0 \mathrm{~mm}$. 
TABLE 1 Patient characteristics and distribution of clinicopathological features in all CLND patients

\begin{tabular}{|c|c|c|}
\hline & $N$ & $\%$ \\
\hline \multicolumn{3}{|l|}{ Gender } \\
\hline Female & 192 & 52.2 \\
\hline Male & 176 & 47.8 \\
\hline \multicolumn{3}{|l|}{ Age (years) } \\
\hline$<40$ & 75 & 20.4 \\
\hline $40-60$ & 185 & 50.3 \\
\hline$\geq 60$ & 108 & 29.3 \\
\hline Mean/median & $51 / 52$ & \\
\hline \multicolumn{3}{|l|}{ Primary tumor site } \\
\hline Head/neck & 1 & 0.3 \\
\hline Upper extremity & 54 & 14.7 \\
\hline Lower extremity & 130 & 35.3 \\
\hline Anterior trunk & 49 & 13.3 \\
\hline Posterior trunk & 134 & 36.4 \\
\hline \multicolumn{3}{|c|}{ Primary melanoma Breslow thickness (mm) } \\
\hline$\leq 1.0$ & 24 & 6.7 \\
\hline $1.01-2.0$ & 46 & 12.8 \\
\hline $2.01-4.0$ & 127 & 35.5 \\
\hline$>4.0$ & 161 & 45.0 \\
\hline Data not available & 10 & \\
\hline Median & 4 & \\
\hline \multicolumn{3}{|c|}{ Primary melanoma level of invasion according to Clark } \\
\hline II & 24 & 6.7 \\
\hline III & 122 & 34.1 \\
\hline IV & 158 & 44.1 \\
\hline $\mathrm{V}$ & 54 & 15.1 \\
\hline Data not available & 10 & \\
\hline \multicolumn{3}{|c|}{ Ulceration of melanoma } \\
\hline No & 112 & 32.3 \\
\hline Yes & 235 & 67.7 \\
\hline Data not available & 21 & \\
\hline \multicolumn{3}{|l|}{ Pathological type } \\
\hline NM & 205 & 66.6 \\
\hline SSM & 76 & 24.6 \\
\hline ALM & 12 & 3.9 \\
\hline LMM & 15 & 4.9 \\
\hline Data not available & 60 & \\
\hline \multicolumn{3}{|c|}{ Location of lymph node dissection } \\
\hline Neck & 1 & 0.3 \\
\hline Axillary & 212 & 57.7 \\
\hline Inguinal & 152 & 41.3 \\
\hline Other/mixed & 3 (axillary-inguinal) & 0.7 \\
\hline \multicolumn{3}{|c|}{ Number of lymph nodes with metastases } \\
\hline 1 & 205 & 56.0 \\
\hline $2-3$ & 125 & 34.2 \\
\hline$\geq 4$ & 36 & 9.8 \\
\hline Data not available & 2 & \\
\hline
\end{tabular}

TABLE 1 continued

\begin{tabular}{|c|c|c|}
\hline & $N$ & $\%$ \\
\hline \multicolumn{3}{|c|}{ Extracapsular extension of lymph node metastases } \\
\hline No & 284 & 77.2 \\
\hline Yes & 84 & 22.8 \\
\hline \multicolumn{3}{|c|}{ Metastases to sentinel nodes only } \\
\hline Yes & 262 & 71.6 \\
\hline No & 104 & 28.4 \\
\hline Data not available & 2 & \\
\hline \multicolumn{3}{|c|}{ Maximal diameter of metastases to sentinel node ${ }^{a}$} \\
\hline$<0.1 \mathrm{~mm}$ & 7 & 2.2 \\
\hline $0.1-1.0 \mathrm{~mm}$ & 105 & 32.7 \\
\hline$>1.0 \mathrm{~mm}$ & 209 & 65.1 \\
\hline \multicolumn{3}{|c|}{ Microanatomic localization of metastases in $\mathrm{SN}^{\mathrm{a}}$} \\
\hline Subcapsular & 18 & 5.6 \\
\hline Combined & 149 & 46.4 \\
\hline Parenchymal & 67 & 20.9 \\
\hline Multifocal & 15 & 4.7 \\
\hline Extensive & 72 & 22.4 \\
\hline \multicolumn{3}{|c|}{ Lymph MM RT-PCR assay result ${ }^{\mathrm{b}}$} \\
\hline Positive & 38 & 27.7 \\
\hline Negative & 99 & 72.3 \\
\hline
\end{tabular}

CLND group patients with regional lymph nodes metastases detected by sentinel lymph node biopsy followed by completion lymph node dissection, $N M$ nodular melanoma, $S S M$ superficial spreading melanoma, $A L M$ acral lentiginous melanoma, $L M M$ lentigo malignant melanoma, $S N$ sentinel lymph node, $M M R T-P C R$ multimarker reverse-transcriptase polymerase chain reaction

a 321 patients

b 137 patients

The location of the metastases was also recorded, according to the Dewar criteria for the microanatomic location of the metastasis. ${ }^{9}$ This was either: subcapsular, parenchymal, combined, multifocal, or extensive.

\section{Lymph Fluid Preparation, RNA Isolation and RT-PCR Methods}

The lymph fluid samples (usually $50-100 \mathrm{ml}$ ) were collected in 137 patients in $24-72 \mathrm{~h}$ after the radical lymphadenectomy (CLND) from routinely used sucking, postoperative drainages. As soon as possible after collection, the samples were centrifuged $(500 \mathrm{~g}, 10 \mathrm{~min})$ and incubated with red blood cell-lysing solution for $10 \mathrm{~min}$ on ice. The samples were centrifuged again, and the pellets were collected. Total cellular RNA was prepared from fresh or frozen pellets as described previously. ${ }^{12}$ RNA was further purified from trace amounts of DNA according to the method recommended by the DNase I (RNase-free) producer (Gibco-BRL), except that one-fourth of the 
recommended amount of DNase I was used. DNase I was inactivated by 10 -min incubation at $65^{\circ} \mathrm{C}$ and phenol extraction. RNA concentrations were determined spectrophotometrically. RNA from the human melanoma cell line MeW151 and from normal and fetal fibroblast lines was isolated as described by Chomczynski and Sacchi. ${ }^{16}$ Before cDNA synthesis, the integrity of each RNA sample was checked by electrophoresis on a denaturing agarose gel. No obvious degradation of the $28 \mathrm{~S}$ and $18 \mathrm{~S}$ RNA bands was noted. The DNA contamination in RNA preparations were checked in PCR assay with human glyceraldehyde-3phosphate dehydrogenase (GAPDH 1 and GAPDH 2) primers and RNA as template. The quality of cDNA was controlled by PCR, with GAPDH 1, GAPDH 2 primers.

The Multi-marker [HTYR, MART1/MelanA, and universal melanoma antigen gene (uMAGE)] RT-PCR assay was carried out as described previously, with minor modifications. ${ }^{10,11}$ For reverse transcription, $2 \mu \mathrm{g}$ RNA was used. The primer sequences and PCR conditions for HTYR and MART1/MelanA amplification and for uMAGE amplification were described in Ruka et al. and in Miyashiro et al., respectively. ${ }^{10,17}$ The solution was supplemented with the remaining RT reagents and SuperScript reverse transcriptase to a final volume of $20 \mu \mathrm{l}$, according to the conditions recommended by the manufacturer (Gibco-BRL). The reaction mixture was incubated at $37^{\circ} \mathrm{C}$ for $1 \mathrm{~h}$. The cDNA product was further purified by phenol/chloroform extraction and precipitation with 2.5 volumes of ethanol. The precipitated pellet was dissolved in $15 \mu \mathrm{l}$ DEPC-treated water. The resulting amplification products $(10 \mu \mathrm{l})$ were analyzed by electrophoresis on a $2 \%$ agarose gel, with DdeI-digested pUC 19 as a molecular weight standard. The positive control in each experiment was cDNA from melanoma cell line MeW151, which is known to express each of the 3 markers.

The lymphatic drainage sample was deemed positive for the presence of melanoma cells if at least 1 melanoma marker was detected by MM RT-PCR. The researchers who performed the PCR assay were blinded to disease status, and those recording the disease status were blinded to the PCR assay results.

\section{Statistical Analyses}

All statistical analyses were performed using R 2.10.1 statistical program ( $\mathrm{R}$ Development Core Team; http://www.R-project.org). Contingency tables were analyzed by the chi-square test. Correlation between primary tumor Breslow thickness and SN metastases size was analyzed with use of Spearman correlation coefficient. For comparison of 2 groups with non-normal distribution nonparametric the Mann-Whitney $U$ test was applied.
For the survival analysis the Kaplan-Meier estimator was used with the log-rank tests for bivariate comparisons. Overall survival (OS) time for the assessment of prognostic value of clinical and pathological parameters was calculated from the date of lymph node dissection (CLND) to the date of the most recent follow-up (censored data) or death (as it was evaluated in the melanoma AJCC staging system). ${ }^{5,18,19}$ Similarly, disease-free survival time (DFS) was calculated from the date of therapeutic lymphadenectomy to the date of the most recent follow-up or disease recurrence.

Clinical and pathological parameters as follow: gender, age ( $<40$ vs. $40-60$ vs. $>60$ years), primary tumor Breslow thickness ( $\leq 1.0$ vs. $1.01-2.0$ vs. $2.01-4.0$ vs. $>4.0 \mathrm{~mm}$ ), presence of ulceration of primary lesion, primary tumor level of invasion according to Clark (II/III vs. IV/V), localization of lymphadenectomy (inguinal vs. axillary), number of lymph nodes with metastases ( 1 vs. 2-3 vs. $\geq 4$ ), presence of extracapsular invasion in involved lymph nodes, size of metastases to $\mathrm{SN}$ according to Rotterdam criteria, microanatomic location of the metastasis and result of lymph fluid MM RT-PCR were tested as a factors affecting patients survival. We have not analyzed the prognostic significance of multiple markers as compared with single markers in lymph fluid MM RT-PCR, because of limited number of cases with positive multiple markers.

In the course of the multivariate analysis of the factors associated with shortened survival time, we used Cox's proportional hazard models, applying the stepwise (forward) model building procedure, including all covariates significant at $20 \%$ level in bivariate analysis. Because of the limited number of patients (137), in whom the postoperative lymph fluid was analyzed with MM RT-PCR, 2 models for multivariate analysis were constructed: I without MM RT-PCR results, and II including RT-PCR results.

The differences were considered statistically significant if the $P$ values were $<.05$.

\section{RESULTS}

\section{RT-PCR and Clinical-Pathological Results}

Positive results for the MM RT-PCR assay were recorded in 38 of 137 analyzed lymph fluid specimens (27.7\%). Positive results for the RT-PCR assay correlated with a higher Breslow thickness $(P<.01)$, the higher number of metastatic regional lymph nodes $(P=.01)$ and an older patients age $(P<.05)$. A significantly higher rate of recurrence was observed in patients with positive RT-PCR results (27 of 38 cases, $71.1 \%$ ) than in those with negative results (49 of 99 cases, $49.5 \% ; P=.02$ ). The pattern of the first recurrences in the MM RT-PCR patients was: 18 
TABLE 2 Correlation of sentinel node tumor burden according to Rotterdam criteria and presence of metastases to nonsentinel nodes

\begin{tabular}{lcc}
\hline $\begin{array}{l}\text { Sentinel node } \\
\text { tumor burden }\end{array}$ & $\begin{array}{l}\text { No additional } \\
\text { nonsentinel nodes } \\
\text { involvement }\end{array}$ & $\begin{array}{l}\text { Additional } \\
\text { nonsentinel } \\
\text { nodes involvement }\end{array}$ \\
\hline$<0.1 \mathrm{~mm}$ & $7(100 \%)$ & $0(0 \%)$ \\
$0.1-1.0 \mathrm{~mm}$ & $86(81 \%)$ & $19(19 \%)$ \\
$>1.0 \mathrm{~mm}$ & $146(69 \%)$ & $63(31 \%)$ \\
\hline
\end{tabular}

cases, distant metastases (66.7\%; mainly lungs); 8 , intransit/local recurrences $29.6 \%$ ); and 1 , the same nodal basin recurrence $(3.7 \%)$.

The distribution of SN tumor burden according the Rotterdam criteria was (Table 1): $<0.1 \mathrm{~mm}, 7$ cases $(2.2 \%) ; 0.1-1.0 \mathrm{~mm}, 105$ cases $(32.7 \%)$; and $>1.0 \mathrm{~mm}$, 209 cases $(65.1 \%)$. The SN tumor burden showed linear correlation with increasing Breslow thickness $(P=.01$; correlation coefficient $r=0.15$ ). The rate of additional non-SN involvement according to Rotterdam criteria for SN tumor burden increased from $0 \%$ in submicrometastases $(<0.1 \mathrm{~mm})$ through $18 \%(0.1-1.0 \mathrm{~mm})$ to $30.6 \%$ in $\mathrm{SN}$ metastases $>1.0 \mathrm{~mm}(P<.01)$ (Table 2$)$.

\section{Survival Analysis}

The median OS and 5-year OS rates were: 59.2 months and $51.5 \%$ (95\% confidence interval [95\% CI]: 44.9\%$59.9 \%$ ), respectively; and the median DFS and 5-year rates were: 29.7 months and $40.5 \%$ (95\% CI: $34.5 \%-47.8 \%$ ), respectively.

The results of univariate analysis of the impact of individual factors on OS and DFS (calculated from the date of lymph node dissection) are shown in Table 3.

According to the univariate analysis, the following factors had a negative impact on overall survival of patients after CLND: higher primary tumor Breslow thickness, ulceration of primary tumor, higher level of invasion in primary melanoma according to Clark, male gender, number of lymph node with metastases $>1$, extracapsular extension of nodal metastases, axillary location of nodal metastases, presence of metastases to additional non-SNs, maximal SN tumor burden $\geq 0.1 \mathrm{~mm}$ (Fig. 1a) and positive result of lymph fluid MM RT-PCR (Fig. 1b).

The following factors had a negative impact on diseasefree survival according to the univariate analysis: male gender, higher primary tumor Breslow thickness, higher level of invasion in primary melanoma according to Clark, ulceration of primary tumor, number of lymph nodes with metastases $>1$, extracapsular extension of nodal metastases, presence of metastases to additional non-SNs, maximal SN tumor burden $\geq 0.1 \mathrm{~mm}$ and positive result of lymph fluid MM RT-PCR.
According to the multivariate analysis, we have confirmed and identified that the most important factors negatively influencing OS are: in model I (without results of lymph MM RT-PCR)—male gender (HR $=2.004 ; 95 \%$ $\mathrm{CI}=1.348-2.976 ; P=.001)$, features of primary tumor [presence of ulceration $(\mathrm{HR}=2.168 ; 95 \% \mathrm{CI}=1.35$ 3.48; $P=.001)$ ], and features of nodal metastases [SN tumor burden $>1.0 \mathrm{~mm} \quad(\mathrm{HR}=1.06 ; 95 \% \mathrm{CI}=1.014$ $1.11 ; P=.010)$ and number of involved nodes $>1$ $(P<.0001)$ ]; and in model 2 (including results of lymph MM RT-PCR) - presence of ulceration of primary melanoma $(\mathrm{HR}=2.17 ; 95 \% \mathrm{CI}=1.12-4.2 ; P=.021)$, SN tumor burden $>1.0 \mathrm{~mm}(\mathrm{HR}=1.13 ; 95 \% \mathrm{CI}=1.05$ $1.21 ; P=.001)]$ and positive result of lymph fluid MM RT-PCR $(\mathrm{HR}=3.24 ; 95 \% \mathrm{CI}=1.76-5.95 ; \quad P<.001)$ (Table 4).

Negative impact on DFS according to multivariate analysis had the following factors: in model I-male gender $\quad(\mathrm{HR}=1.46 ; \quad 95 \% \quad \mathrm{CI}=1.017-2.092 ; \quad P=.04)$, features of primary tumor [higher Breslow thickness $>1.0 \mathrm{~mm}(P=.019)$, higher level of invasion according to Clark $(P=.013)$, and presence of ulceration $(\mathrm{HR}=1.955$; 95\% CI $=1.26-3.04 ; P=.003)]$, and features of nodal metastases [number of involved nodes $>1(P<.0001)$ ]; and in model 2-presence of ulceration of primary melanoma $(\mathrm{HR}=2.33 ; 95 \% \mathrm{CI}=1.32-4.27 ; P=.006), \mathrm{SN}$ tumor burden $>1.0 \mathrm{~mm}(\mathrm{HR}=1.07 ; 95 \% \mathrm{CI}=1.006$ 1.144; $P=.032$ ), number of involved nodes $>1$ $(P=.023)$, and positive result of lymph fluid MM RT$\mathrm{PCR} \quad(\mathrm{HR}=2.23 ; \quad 95 \% \quad \mathrm{CI}=1.27-3.9 ; \quad P=.005)$ (Table 5).

\section{DISCUSSION}

The presence of nodal metastases in patients with primary cutaneous melanoma is the most important factor that adversely affects the biological behavior and is related to poor prognosis. ${ }^{1-4,20,21}$ Sentinel node biopsy is perhaps the greatest contribution in surgical oncology of last 2 decades for assessment of the stage of regional nodes. ${ }^{22}$ Along with the more extensive pathological protocols of sentinel node examinations (using serial sectioning and immunohistochemistry) SNB is currently the most powerful technique for the identification of micrometastases to regional lymph nodes. ${ }^{23,24}$ There is a worldwide agreement about the negative prognostic implications of node positivity in cutaneous melanoma, but the clinical significance of tiny tumor deposits is still debatable. We have confirmed in our group of patients that the Rotterdam criteria for assessment of tumor burden in SNs gives the independent prognostic information and may in the future replace other factors related to nodal metastases (as number of metastatic nodes or extracapsular involvement-the factors, which 
TABLE 3 The 5-year overall survival (OS) and disease-free survival (DFS) rate in group after completion lymph node dissection (CLND) because of positive sentinel nodes according to clinicalpathological and molecular features of primary tumor and nodal metastases (calculated from the date of CLND)
CLND group patients with regional lymph nodes metastases detected by sentinel lymph node biopsy followed by completion lymph node dissection, $S N$ sentinel lymph node, $M M R T-P C R$ multimarker reverse-transcriptase polymerase chain reaction, $N A$ not available

\begin{tabular}{llll}
\hline $\begin{array}{l}\text { 5-year OS rate } \\
\text { (95\% confidence interval) }\end{array}$ & $P$ value & $\begin{array}{l}\text { 5-year DFS rate } \\
(95 \% \text { confidence interval })\end{array}$ & $P$ value \\
\hline
\end{tabular}

Primary melanoma Breslow thickness $(\mathrm{mm})$

$\begin{array}{ll}\leq 1.0 & 77.8(54.9-100) \\ 1.01-2.0 & 68.6(51.2-91.8) \\ 2.01-4.0 & 60.5(50.2-73.0) \\ >4.0 & 38.7(31.7-47.3)\end{array}$

.0001

$39.6(10.0-87.5)$

.0001

Ulceration of melanoma

$\begin{array}{llll}\text { No } & 66.8(56.9-78.4) & <.0001 & 54.5(44.5-66.7) \\ \text { Yes } & 39.6(32.7-47.9) & & 29.0(22.5-37.2)\end{array}$

.0000

Primary melanoma level of invasion according to Clark

$\begin{array}{llll}\text { II-III } & 57.6(33.8-81.2) & .0083 & 48.5(13.1-69.0) \\ \text { IV-V } & 39.5(27.5-56.8) & & 28.5(17.5-43.8)\end{array}$

0009

Location of lymph node dissection

$\begin{array}{ll}\text { Axillary } & 42.6(35.7-51.6) \\ \text { Inguinal } & 58.6(50.0-68.7) \\ \text { Gender } & \\ \text { Female } & 58.9(51.2-67.7) \\ \text { Male } & 33.6(25.6-44.1) \\ \text { Age (years) } & \\ <40 & 58.2(46.8-72.4) \\ 40-60 & 48.1(33.9-62.5) \\ \geq 60 & 39.8(17.4-63.5)\end{array}$

$.0098 \quad 34.1(27.2-42.7)$

$44.7(36.2-55.2)$

$.0001 \quad 42.6(35.1-51.8)$

.04

$29.1(21.4-39.5)$

$.2054 \quad 48.6(37.2-63.5)$

.11

$34.8(19.3-54.2)$

$35.4(23.8-62.2)$

Number of lymph nodes with metastases

$\begin{array}{ll}1 & 59.6(52.3-67.9) \\ 2-3 & 36.5(27.7-47.9) \\ \geq 4 & 29.3(15.2-56.5)\end{array}$

$<.0001$

$50.1(42.7-58.8)$

$<.0001$

$26.3(18.6-37.2)$

$11.8(3.7-38.0)$

Extracapsular extension of lymph nodes metastases

$\begin{array}{llll}\text { No } & 53.5(47.1-60.8) & <.0001 & 42.2(35.9-49.6) \\ \text { Yes } & 26.9(16.7-40.7) & & 18.6(10.8-32.2)\end{array}$

Metastases to additional non-SNs

$\begin{array}{ll}\text { Absent } & 55.9(46.9-72.3) \\ \text { Present } & 32.5(26.3-48.5)\end{array}$

.0004

$48.7(35.8-55.4)$

Maximal diameter of metastases to sentinel node

$\begin{array}{ll}<0.1 \mathrm{~mm} & 83.8(58.3-100.0) \\ 0.1-1.0 \mathrm{~mm} & 66.2(55.6-78.8)\end{array}$

.0006

$83.3(58.3-100.0)$

$>1.0 \mathrm{~mm}$

$40.2(33.1-48.8)$

$55.2(44.5-68.5)$

$30.0(23.5-38.4)$

Microanatomic localization of metastases in SN

$\begin{array}{ll}\text { Subcapsular } & 43.6(25.1-75.6) \\ \text { Combined } & 65.8(52.6-82.2) \\ \text { Parenchymal } & 59.5(48.3-73.2) \\ \text { Multifocal } & 39.4(30.8-50.3) \\ \text { Extensive } & 41.2(28.1-60.3)\end{array}$

.07

$38.0(21.7-66.3)$

$42.0(29.7-59.4)$

$45.0(33.7-60.0)$

$34.1(26.0-44.9)$

$26.5(14.5-48.3)$

Lymph MM RT-PCR assay result

$\begin{array}{lccc}\text { Positive } & 46.7(36.3-59.9) & .0007 & 39.0(29.0-52.4) \\ \text { Negative } & 0(\text { NA-NA) } & & 21.1(10.5-42.4)\end{array}$

$<.0001$ independent significance was confirmed in our previous analysis not including $\mathrm{SN}$ deposit size). ${ }^{6}$ The group of patients with submicrometastases $<0.1 \mathrm{~mm}$, although responsible for only $2.2 \%$ of positive SNs in our group of patients (what might be related to rather high median Breslow thickness of primaries and explained by 
FIG. 1 Overall survival (calculated from the date of lymphadenectomy) in the group of patients after completion lymph node dissection for regional lymph nodes metastases detected by sentinel lymph node biopsy according to a sentinel node tumor burden (Rotterdam criteria) $(P=.0006)$ and $\mathbf{b}$ the results of lymph fluid multimarker RT-PCR assay $(P=.0007)$
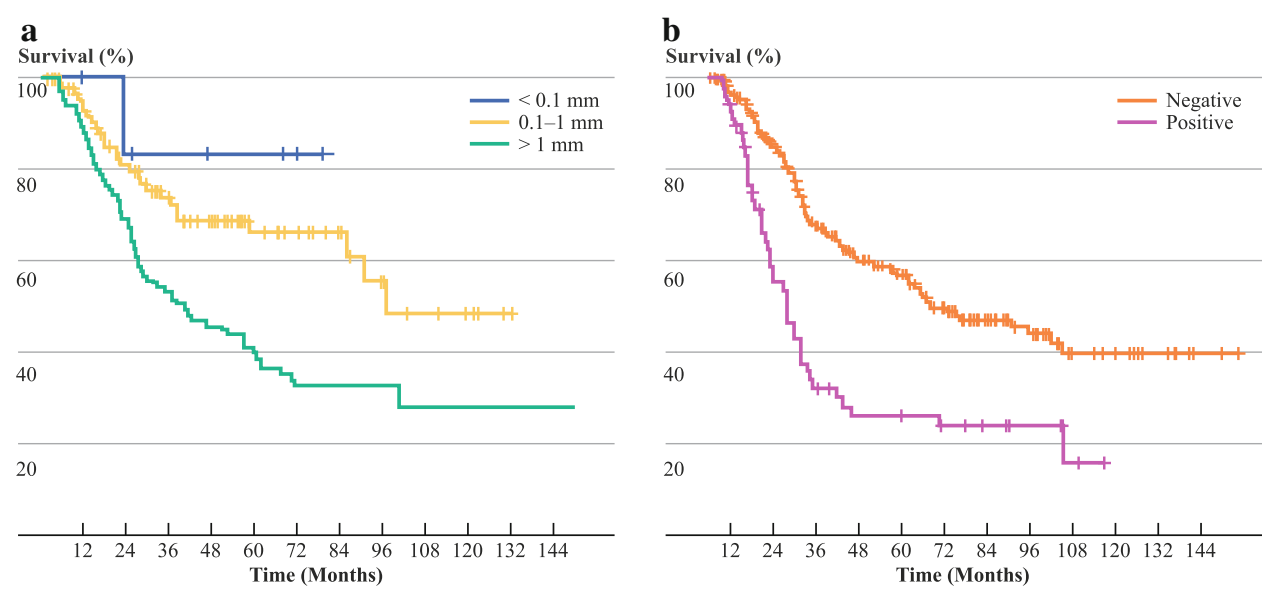

TABLE 4 Summary of the multivariate analysis of selected factors associated with overall survival (model 1, without results of lymph MM RTPCR; model 2, including results of lymph MM RT-PCR)

\begin{tabular}{|c|c|c|c|c|c|c|}
\hline \multirow[t]{2}{*}{ Variable } & \multicolumn{3}{|c|}{ Model $1(N=321)$} & \multicolumn{3}{|c|}{ Model $2(N=137)$} \\
\hline & $P$ value & HR & HR $95 \%$ CI & $P$ value & HR & HR 95\% CI \\
\hline \multicolumn{7}{|l|}{ Gender } \\
\hline Male vs. female & .001 & 0.499 & $0.336-0.742$ & & & \\
\hline \multicolumn{7}{|c|}{ Primary melanoma level of invasion according to Clark } \\
\hline Clark III & .216 & 0.580 & $0.245-1.374$ & & & \\
\hline Clark IV & .574 & 1.266 & $0.557-2.875$ & & & \\
\hline Clark V & .871 & 0.929 & $0.380-2.272$ & & & \\
\hline \multicolumn{7}{|l|}{ Ulceration of melanoma } \\
\hline Present vs absent & .001 & 2.168 & $1.349-3.483$ & .021 & 2.17 & $1.124-4.201$ \\
\hline \multicolumn{7}{|c|}{ Maximal diameter of metastases to sentinel node } \\
\hline$>1.0 \mathrm{~mm}$ versus $0.1-1.0 \mathrm{~mm}$ & .010 & 1.061 & $1.014-1.110$ & .001 & 1.128 & $1.053-1.209$ \\
\hline \multicolumn{7}{|c|}{ Number of lymph nodes with metastases } \\
\hline $2-3$ & .111 & 1.409 & $0.924-2.147$ & & & \\
\hline$\geq 4$ & .006 & 2.692 & $1.328-5.453$ & & & \\
\hline \multicolumn{7}{|l|}{ Lymph MM RT-PCR assay result } \\
\hline Positive vs. negative & & & & $<.001$ & 3.24 & $1.78-5.95$ \\
\hline
\end{tabular}

$H R$ hazard ratio, $C I$ confidence interval, $M M R T-P C R$ multimarker reverse-transcriptase polymerase chain reaction, $N A$ not available

demonstrated in our analysis existing the linear correlation between primary tumor thickness and SN tumor deposit size), was characterized by excellent prognosis with 5-year OS exceeding $80 \%$. Moreover, we have confirmed that, the tumor burden assessed by these criteria is closely associated with the presence of metastases to additional non-SNs after CLND, what has been suggested previously. ${ }^{7,8,25,26}$ The presence of positive non-SNs is per se highly negative prognostic factor for patient survival analyzed recently by other authors. ${ }^{27,28}$

The other important result of our study is the confirmation of the important prognostic impact of the MM RTPCR assay proposed by us for assessment of the presence of melanoma molecular markers in lymph fluid collected routinely after lymph node dissection. ${ }^{10-12}$ In the multivariate analysis model including the results of lymph MM RT-PCR, we have demonstrated that positive result of this assay is the most important independent prognostic factor (beyond the primary tumor ulceration and SN tumor burden according to Rotterdam criteria) for poor survival in group of patients limited to SN-positive cases. The results of RT-PCR analyses of melanoma circulating cells in blood specimens (especially from single, not serial determination studies) and of detection of melanoma molecular markers in SNs are controversial. ${ }^{29-47}$ The analysis of lymph MM RT-PCR gave more consistent data, which may be related to high volume of lymph fluid in patients with confirmed lymphatic dissemination of the disease (in the blood tumor cells may be present at extremely low concentrations and tumor shedding may be intermittent) and using multiple 
Table 5 Multivariate analysis of selected factors influencing diseasefree survival in CLND patients (with regional lymph node metastases detected by sentinel lymph node biopsy followed by completion lymph node dissection) [model I, without results of lymph MM RTPCR; model 2, including results of lymph MM RT-PCR)

\begin{tabular}{|c|c|c|c|c|c|c|}
\hline \multirow[t]{2}{*}{ Variable } & \multicolumn{3}{|c|}{ Model $1(N=321)$} & \multicolumn{3}{|c|}{ Model $2(N=137)$} \\
\hline & $P$ value & HR & HR 95\% CI & $P$ value & HR & HR $95 \%$ CI \\
\hline \multicolumn{7}{|l|}{ Gender } \\
\hline Male vs. female & .040 & 0.685 & $0.478-0.983$ & & & \\
\hline \multicolumn{7}{|c|}{ Primary melanoma Breslow thickness (mm) } \\
\hline $1.01-2.0$ & .292 & 2.301 & $0.906-5.844$ & & & \\
\hline $2.01-4.0$ & .46 & 0.562 & $0.229-1.383$ & & & \\
\hline$>4.0$ & .855 & 0.636 & $0.405-0.997$ & & & \\
\hline \multicolumn{7}{|c|}{ Primary melanoma level of invasion according to Clark } \\
\hline Clark III & .216 & 0.645 & $0.286-1.457$ & & & \\
\hline Clark IV & .574 & 1.354 & $0.606-3.024$ & & & \\
\hline Clark V & .871 & 0.922 & $0.388-2.194$ & & & \\
\hline \multicolumn{7}{|l|}{ Ulceration of melanoma } \\
\hline Present vs. absent & .003 & 1.955 & $1.258-3.039$ & .006 & 0.429 & $0.234-0.786$ \\
\hline \multicolumn{7}{|c|}{ Maximal diameter of metastases to sentinel node } \\
\hline$>1.0 \mathrm{~mm}$ vs. $0.1-1.0 \mathrm{~mm}$ & & & & .032 & 1.073 & $1.006-1.144$ \\
\hline \multicolumn{7}{|c|}{ Number of lymph nodes with metastases } \\
\hline $2-3$ & .101 & 1.376 & $0.940-2.016$ & .006 & 0.322 & $0.143-0.723$ \\
\hline$\geq 4$ & $<.001$ & 3.191 & $1.806-5.641$ & .031 & 0.426 & $0.196-0.926$ \\
\hline \multicolumn{7}{|c|}{ Lymph MM RT-PCR assay result } \\
\hline Positive vs. negative & & & & .005 & 0.449 & $0.256-0.787$ \\
\hline
\end{tabular}

target markers, including tyrosinase, MART1, and uMAGE. Using multimarker assay might increase sensitivity of our test. ${ }^{42,48}$ The choice of the set of pigmented cell-specific markers for our MM RT-PCR guarantees the covering the different melanoma cells phenotypes and comprises the most commonly investigated marker, transcribed actively mainly in melanocytes-tyrosinase, MART-1 frequently expressed by melanoma cells mainly in locoregional stage, and UMAGE designed for detection of MAGE-A1, MAGE-A3, MAGE-A5, MAGE-A6, and MAGE-A12. ${ }^{36,43,44,49-51}$ However, the final value of this test for selecting of patients at higher risk of relapses and prediction of their prognosis should be confirmed in other cohort of patients. The results of our study should not be translated to all populations, because they are based on the group of relatively advanced primary lesions with high percentage of ulcerated melanomas and prevalence of the sentinel nodes metastatic deposits larger than $1 \mathrm{~mm}$.

To summarize, we have demonstrated that SLN tumor burden categories according Rotterdam criteria and the positive result of lymph MM-RT-PCR assay had additional, independent prognostic value in SN-positive melanoma patients, showing significant correlation with shorter DFS and OS. We suggest including the Rotterdam criteria for assessment of tumor burden in SNs and RT-
PCR analysis of lymphatic fluid in future clinical trials involving selective lymphadenectomies in patients with cutaneous melanoma.

ACKNOWLEDGMENT We thank D. Rabczenko for statistical advice. The study was supported by the Polish Ministry of Science grant No. N403 476534.

OPEN ACCESS This article is distributed under the terms of the Creative Commons Attribution Noncommercial License which permits any noncommercial use, distribution, and reproduction in any medium, provided the original author(s) and source are credited.

\section{REFERENCES}

1. Morton DL, Thompson JF, Cochran AJ, Mozzillo N, Elashoff R, Essner R, et al. Sentinel-node biopsy or nodal observation in melanoma. $N$ Engl J Med. 2006;355:1307-17.

2. Gershenwald JE, Thompson W, Mansfield PF, Lee JE, Colome MI, Tseng $\mathrm{CH}$, et al. Multi-institutional melanoma lymphatic mapping experience: the prognostic value of sentinel lymph node status in 612 stage I or II melanoma patients. J Clin Oncol. 1999; 17:976-83.

3. Statius Muller MG, van Leeuwen PA, de Lange-De Klerk ES, van Diest PJ, Pijpers R, Ferwerda CC, et al. The sentinel lymph node status is an important factor for predicting clinical outcome in patients with Stage I or II cutaneous melanoma. Cancer. 2001;91:2401-8.

4. Nowecki ZI, Rutkowski P, Nasierowska-Guttmejer A, Ruka W. Sentinel lymph node biopsy in melanoma patients with clinically 
negative regional lymph nodes-one institution's experience. Melanoma Res. 2003;13:35-43.

5. Balch CM, Gershenwald JE, Soong S-J, Thompson JF, Atkins MB, Byrd DR, et al. Final version of 2009 AJCC melanoma staging and classification. J Clin Oncol. 2009;27:6199-206.

6. Nowecki ZI, Rutkowski P, Michej W. The survival benefit to patients with positive sentinel node melanoma after completion lymph node dissection may be limited to the subgroup with a primary lesion Breslow thickness greater than 1.0 and less than or equal to 4 mm (pT2-pT3). Ann Surg Oncol. 2008;15:2223-34.

7. van Akkooi ACJ, de Wilt JHW, Verhoef C, Schmitz PIM, van Geel AN, Eggermont AMM, et al. Clinical relevance of melanoma micrometastases $(<0.1 \mathrm{~mm})$ in sentinel nodes: are these nodes to be considered negative? Ann Oncol. 2006;17:1578-85.

8. van Akkooi ACJ. Nowecki ZI, Voit C, Schafer-Hesterberger G, Michej W, de Wilt JHW, et al. Sentinel node burden according to the Rotterdam criteria is the most important prognostic factor for survival in melanoma patients. A multicenter study in $388 \mathrm{SN}$ positive patients. Ann Surg. 2008;248:949-55.

9. Dewar DJ, Newell B, Green MA, Topping AP, Powell BW, Cook MG. The microanatomic location of metastatic melanoma in sentinel lymph nodes predicts nonsentinel lymph node involvement. J Clin Oncol. 2004;22:3345-9.

10. Ruka W, Rutkowski P, Nowecki ZI, Kulik J, Nasierowska-Guttmejer A, Siedlecki JA. Detection of melanoma cells in the lymphatic drainage after lymph node dissection in melanoma patients by using two-marker reverse transcriptase-polymerase chain reaction assay. Ann Surg Oncol. 2004;11:988-997.

11. Nowecki ZI, Rutkowski P, Kulik J, Siedlecki JA, Ruka W. Molecular and biochemical testing in stage III melanoma: multimarker reverse transcriptase-polymerase chain reaction assay of lymph fluid after lymph node dissection and preoperative serum lactate dehydrogenase level. Br J Dermatol. 2008;159: 597-605.

12. Rutkowski P, Nowecki ZI, Kulik J, Ruka W, Siedlecki JA. Molecular staging by multimarker reverse transcriptase-polymerase chain reaction assay of lymphatic drainage and blood from melanoma patients after lymph node dissection. Melanoma Res. 2008;18:246-52.

13. Karakousis CP. Therapeutic node dissections in malignant melanoma. Semin Surg Oncol. 1998;14:291-301.

14. Eggermont AMM, Suciu S, MacKie R, Ruka W, Testori A, Kruit $\mathrm{W}$, et al. Post-surgery adjuvant therapy with intermediate doses of interferon alfa $2 \mathrm{~b}$ versus observation in patients with stage IIb/III melanoma (EORTC 18952): randomized controlled trial. Lancet. 2005;366:1189-96.

15. Cook MG, Green MA, Anderson B, Eggermont AM, Ruiter DJ, Spatz A, et al. The development of optimal pathological assessment of sentinel lymph nodes for melanoma. J Pathol. 2003;200:314-9.

16. Chomczynski P, Sacchi N. Single step method of RNA isolation by acid guanidinium thiocyanate-phenol-chloroform extraction. Anal Biochem. 1987;162:156-9.

17. Miyashiro I, Kuo C, Huynh K, Iida A, Morton D, Bilchik A, et al. Molecular strategy for detecting metastatic cancers with use of multiple tumor-specific MAGE-A genes. Clin Chem. 2001;47: 505-12.

18. Balch CM, Soong SJ, Gershenwald JE, Thompson JF, Reintgen DS, Cascinelli N, et al. Prognostic factors analysis of 17,600 melanoma patients: validation of the American Joint Committee on Cancer melanoma staging system. J Clin Oncol. 2001;19: 3622-34.

19. Berd D, Mastrangelo MJ, Sato T. Calculation of survival of patients with stage III melanoma. J Clin Oncol. 2005;23:9427.

20. van Akkooi ACJ, de Wilt JHW, Verhoef C, Graveland WJ, van Geel, Kliffen M, et al. High positive sentinel node identification rate by EORTC Melanoma Group protocol. Prognostic indicators of metastatic patterns after sentinel node biopsy in melanoma. Eur J Cancer. 2006;42:372-80.

21. Testori A, De Salvo GL, Montesco MC, Trifirò G, Mocellin S, Landi $\mathrm{G}$, et al. Clinical considerations on sentinel node biopsy in melanoma from an Italian multicentric study on 1,313 patients (SOLISM-IMI). Ann Surg Oncol. 2009;16:2018-27.

22. Testori A, Rutkowski P, Marsden J, Bastholt L, Chiarion-Sileni V, Hauschild A, et al. Surgery and radiotherapy in the treatment of cutaneous melanoma. Ann Oncol. 2009; 20 (Suppl. 6):vi22-9.

23. Balch CM, Cascinelli N. Editorials: Sentinel-node in melanoma. N Engl J Med. 2006;355:1370-2.

24. Doubrovsky A, de Wilt JHW, Scolyer RA, McCarthy WH, Thompson JF. Sentinel node biopsy provides more accurate staging than elective lymph node dissection in patients with cutaneous melanoma. Ann Surg Oncol. 2004;11:829-36.

25. Gershenwald JE, Andtbacka RHI, Prieto VG, Johnson MM, Diwan $\mathrm{AH}$, Lee JE, et al. Microscopic tumor burden in sentinel lymph nodes predicts synchronous nonsentinel lymph node involvement in patients with melanoma. $J$ Clin Oncol. 2008;26:4296-303.

26. Govindarajan A, Ghazarian DM, McCready DR, Leong WL. Histological features of melanoma sentinel lymph node metastases associated with status of the completion lymphadenectomy and rate of subsequent relapse. Ann Surg Oncol. 2007;14:906-12.

27. Ghaferi AA, Wong SL, Johnson TM, Lowe L, Chang AE, Cimmino VM, et al. Prognostic significance of a positive nonsentinel lymph node in cutaneous melanoma. Ann Surg Oncol. 2009; $16: 2978-84$.

28. Jakub JW, Huebner M, Shivers S, Nobo C, Puleo C, Harmsen WS, et al. The number of lymph nodes involved with metastatic disease does not affect outcome in melanoma patients as long as all disease is confined to the sentinel lymph node. Ann Surg Oncol. 2009;16:2245-51.

29. Kuo CT, Hoon DS, Takeuchi H, Turner R, Wang HJ, Morton DL, et al. Prediction of disease outcome in melanoma patients by molecular analysis of paraffin-embedded sentinel lymph nodes. $J$ Clin Oncol. 2003;21:3566-72.

30. McMasters KM, Noyes RD, Reintgen DS, Goydos JS, Beitsch PD, Davidson BS, et al. For The Sunbelt Melanoma Trial. Lessons learned from the Sunbelt Melanoma Trial. J Surg Oncol. 2004;86:212-23.

31. Osella-Abate S, Savoia P, Quaglino P, Fierro MT, Leporati C, Ortoncelli $\mathrm{M}$, et al. Tyrosinase expression in the peripheral blood of stage III melanoma patients is associated with a poor prognosis: a clinical follow-up study of 110 patients. $\mathrm{Br} J$ Cancer. 2003;89:1457-62.

32. Mocellin S, Hoon DSB, Pilati P, Rossi CR, Nitti D. Sentinel lymph node molecular ultrastaging in patients with melanoma: a systematic review and meta-analysis of prognosis. J Clin Oncol. 2007;25:1588-95.

33. Hilari JM, Mangas C, Xi L, Paradelo C, Ferrándiz C, Hughes SJ, et al. Molecular staging of pathologically negative sentinel lymph nodes from melanoma patients using multimarker, quantitative real-time RT-PCR. Ann Surg Oncol. 2009;16:177-85.

34. Voit C, Kron M, Rademaker J, Schwürzer-Voit M, Sterry W, Weber L, et al. Molecular staging in stage II and III melanoma patients and its effect on long-term survival. J Clin Oncol. 2005; 23:1218-27.

35. Voit CA, Schaefer-Hesterberg G, Kron M, van Akkooi ACJ, Rademaker J, Lukowsky A, et al. Impact of molecular staging methods in primary melanoma: reverse-transcriptase polymerase chain reaction (RT-PCR) of ultrasound-guided aspirate of the sentinel node does not improve diagnostic accuracy, but RT-PCR of peripheral blood does predict survival. J Clin Oncol. 2008; 26:5742-7. 
36. Palmieri G, Ascierto PA, Perrone F, Satriano SM, Ottaiano A, Daponte A, et al. Prognostic value of circulating melanoma cells detected by reverse transcriptase-polymerase chain reaction. $J$ Clin Oncol. 2003;21:767-73.

37. Scoggins CR, Ross MI, Reintgen DS, Noyes RD, Goydos JS, Beitsch PD, et al. Prospective multi-institutional study of reverse transcriptase polymerase chain reaction for molecular staging of melanoma. J Clin Oncol. 2006;24:2849-57.

38. Micciolo R, Boi S, Paoli L, Cristofolini P, Girlando S, Palma PD, et al. Clinical relevance of sentinel lymph node status examined with conventional histology and molecular biology. Tumori. 2009;95:298-302.

39. Visús C, Andres R, Mayordomo JI, Martinez-Lorenzo MJ, Murillo L, Sáez-Gutiérrez B, et al. Prognostic role of circulating melanoma cells detected by reverse transcriptase-polymerase chain reaction for tyrosinase mRNA in patients with melanoma. Melanoma Res. 2007;17:83-9.

40. Steen, S, Nemunaitis J, Fisher T, Kuhn J. Circulating tumor cells in melanoma: a review of the literature and description of a novel technique. Proc (Bayl Univ Med Cent). 2008;21:127-32.

41. Shivers SC, Wang X, Li W, Joseph E, Messina J, Glass LF, et al. Molecular staging of malignant melanoma: correlation with clinical outcome. JAMA. 1998;280:1410-5.

42. Hoon DS, Bostick P, Kuo C, Okamoto T, Wang HJ, Elashoff R, et al. Molecular markers in blood as surrogate prognostic indicators of melanoma recurrence. Cancer Res. 2000;60:2253-7.

43. Tsao H, Nadiminti U, Sober AJ, Bigby M. A meta-analysis of reverse transcriptase-polymerase chain reaction for tyrosinase mRNA as a marker for circulating tumor cells in cutaneous melanoma. Arch Dermatol. 2001;137:325-30.

44. Smith B, Selby P, Southgate J, Pittman K, Bradley C, Blair GE. Detection of melanoma cells in peripheral blood by means of reverse transcriptase and polymerase chain reaction. Lancet. 1991;338:1227-9.
45. Kulik J, Nowecki ZI, Rutkowski P, Ruka W, Rochowska M, Skurzak H, et al. Detection of circulating melanoma cells in peripheral blood by a two-marker RT-PCR assay. Melanoma Res. 2001;11:65-73.

46. Szenajch J, Jasinski B, Synowiec A, Kulik J, Chomicka M, Struzyna J, et al. Prognostic value of multiple reverse transcription-PCR tyrosinase testing for circulating neoplastic cells in malignant melanoma. Clin Chem. 2003;49:1450-7.

47. Szenajch J, Jasinski B, Kozak A, Kulik J, Chomicka M, Struzyna $\mathrm{J}$, et al. Multiple RT-PCR tyrosinase testing reveals that melanoma cells circulate in the blood of melanoma patients at the frequency more than 10 times below the detection threshold. Melanoma Res. 2002;12:399-401.

48. Keilholz U, Goldin-Lang P, Bechrakis NE, Max N, Letsch A, Schmittel A, et al. Quantitative detection of circulating tumor cells in cutaneous and ocular melanoma and quality assessment by real-time reverse transcriptase-polymerase chain reaction. Clin Cancer Res. 2004;10:1605-12.

49. Curry BJ, Myers K, Hersey P. MART-1 is expressed less frequently on circulating melanoma cells in patients who develop distant compared with locoregional metastases. J Clin Oncol. 1999; 17:2562-71.

50. Schittek B, Bodingbauer Y, Ellwanger U, Blaheta HJ, Garbe C. Amplification of MelanA messenger RNA in addition to tyrosinase increases sensitivity of melanoma cell detection in peripheral blood and is associated with the clinical stage and prognosis of malignant melanoma. Br J Dermatol. 1999;141:306.

51. Miyashiro I, Kuo C, Huynh K, Iida A, Morton D, Bilchik A, et al. Molecular Strategy for detecting metastatic cancers with use of multiple tumor-specific MAGE-A. Genes Clin Chem. 2001; 47:505-12. 